\title{
Minimum amount of nano-sized nickel particles to enhance the strength of alumina
}

\author{
Wei-Hsing Tuan ${ }^{\mathrm{a}, *}$, Jiang-Rung Chen ${ }^{\mathrm{a}}$, Tsong-Jen Yang ${ }^{\mathrm{b}}$ \\ a Department of Materials Science and Engineering, National Taiwan University, Taipei, Taiwan \\ ${ }^{\mathrm{b}}$ Department of Materials Science and Engineering, Fa-Chia University, Taichung, Taiwan \\ Received 19 January 2007; received in revised form 5 March 2007; accepted 16 March 2007 \\ Available online 6 June 2007
}

\begin{abstract}
Previous studies demonstrated that the strength of alumina could be enhanced by incorporating $>5$ vol. $\%$ nano-sized nickel particles. In the present study, the possibility of using a much smaller amount, $<0.5 \mathrm{vol} . \%$, of nano-sized $\mathrm{Ni}$ particles to improve the mechanical properties of $\mathrm{Al}_{2} \mathrm{O}_{3}$ is explored. As the $\mathrm{Ni}$ content is low, the densification of $\mathrm{Al}_{2} \mathrm{O}_{3}$ is affected little and the Ni inclusions remain small after pressureless sintering at $1600^{\circ} \mathrm{C}$. The presence of $\mathrm{Ni}$ inclusions can refine the matrix grains; the strength of $\mathrm{Al}_{2} \mathrm{O}_{3}$ matrix is consequently enhanced.
\end{abstract}

(C) 2007 Elsevier Ltd. All rights reserved.

Keywords: B. Nanocomposites; Grain size; C. Strength; D. $\mathrm{Al}_{2} \mathrm{O}_{3}$

\section{Introduction}

The strength of ceramics can be enhanced through the refinement of the microstructure. ${ }^{1,2}$ One of the most effective methods to reduce the grain size is through the addition of second phase particles. Most previous studies added more than 5 vol. $\%$ inclusions to prohibit the growth of matrix grains. ${ }^{3-5}$ Two penalties accompany the addition of a large amount of second phase. The first penalty is the drop of sintering activity. ${ }^{5}$ Expensive processing techniques, such as hot-pressing, are usually needed to achieve densification. ${ }^{3}$ The second one is the coarsening of the inclusions during sintering. The possibility of preparing the nanocomposite is often ruined due to such a coalescence process. ${ }^{4}$ In order to avoid these penalties, the alternative of using a smaller amount of second phase is explored in the present study. The success of this alternative is evaluated by the measurement of strength.

In the present study, the $\mathrm{Al}_{2} \mathrm{O}_{3}-\mathrm{Ni}$ system is used as the model system to evaluate the feasibility of using a very small amount of second phase to tailor the microstructure. The solubility between $\mathrm{Al}_{2} \mathrm{O}_{3}$ and $\mathrm{Ni}$ is very low. ${ }^{3-5}$ Furthermore, the strength of $\mathrm{Al}_{2} \mathrm{O}_{3}$ is enhanced significantly by adding nano-sized $\mathrm{Ni}$ particles.

\footnotetext{
* Corresponding author. Tel.: +88622365 9800; fax: +886223634562.

E-mail address: tuan@ccms.ntu.edu.tw (W.-H. Tuan).
}

For example, the strength of an alumina has been enhanced by $54 \%$ after the addition of $5 \mathrm{vol} . \%$ of $100 \mathrm{~nm} \mathrm{Ni}$ particles. ${ }^{4}$ However, the coarsening of nano-sized Ni particles, especially above the melting point of $\mathrm{Ni}\left(1453^{\circ} \mathrm{C}\right)$, is very fast during the densification process. ${ }^{5}$ Therefore, it imposes serious challenges for the preparation of $\mathrm{Al}_{2} \mathrm{O}_{3} / \mathrm{Ni}$ nanocomposites. In the present study, a very small amount, $0.03-0.21 \mathrm{vol}$.\%, of nanosized $\mathrm{Ni}$ particles is added into $\mathrm{Al}_{2} \mathrm{O}_{3}$. The nanocomposites are prepared by pressureless sintering at a temperature of $1600^{\circ} \mathrm{C}$. The microstructure-strength relationship of the nanocomposites is determined.

\section{Experimental}

An alumina (TM-DAR, Taimei Chem. Co. Ltd., Tokyo, Japan) powder was milled by ball milling in de-ionized water for $24 \mathrm{~h}$. The milling media used was yttria-stabilized zirconia balls. Ammonia was added drop by drop into the slurry to reach a $\mathrm{pH}$ value of 9.2. After soaking for $10 \mathrm{~min}$, the slurry was filtered, the powder washed and dried. Various amounts $(0-210 \mathrm{~g})$ of nickel nitrate, $\mathrm{Ni}\left(\mathrm{NO}_{3}\right)_{2} \cdot 6 \mathrm{H}_{2} \mathrm{O}$ (Showa Chem. Co., Japan), was added into distilled water. The $\mathrm{pH}$ value of the nickel nitrate solution was also adjusted to 9.2. The alumina powder with the amount of $300 \mathrm{~g}$ was poured into the nickel nitrate solutions $\left(1500 \mathrm{~cm}^{3}\right)$ and then stirred for $30 \mathrm{~min}$. The $\mathrm{Ni}^{2+}$ ion could then be adsorbed onto the surface of the $\mathrm{Al}_{2} \mathrm{O}_{3}$ particles. The resulting powder 
mixtures after coating were filtered and washed with water for several times. The powder mixtures were reduced in pure hydrogen at $550^{\circ} \mathrm{C}$ for $1 \mathrm{~h}$, followed by ball milling in ethyl alcohol for $24 \mathrm{~h}$. A pure $\mathrm{Al}_{2} \mathrm{O}_{3}$ powder was also prepared with the same technique. The amount of $\mathrm{Ni}$ in the powder mixtures was determined by using the inductive coupled plasma-atomic emission spectroscopy (ICP-AES, 3000DV, Perkin-Elmer, Optima, USA).

Green compacts with the dimensions of $7 \mathrm{~mm} \times 6 \mathrm{~mm} \times$ $50 \mathrm{~mm}$ were formed by uniaxially pressing at $44 \mathrm{MPa}$. The compacts were then sintered within a covered graphite mold at $1600{ }^{\circ} \mathrm{C}$ for $1 \mathrm{~h}$. The heating and cooling rates were $5^{\circ} \mathrm{C} / \mathrm{min}$. A graphite powder was also used to cover the green compacts. A reducing atmosphere, carbon monoxide mainly, was generated during sintering. The final density of the specimens was determined by the Archimedes method. Thermal etching was conducted at $1450{ }^{\circ} \mathrm{C}$ for $1 \mathrm{~h}$ to reveal the grain boundaries. The microstructure was observed by using scanning electron microscopy (SEM). Polished surfaces were prepared by grinding and polishing with diamond paste to $3 \mu \mathrm{m}$ and with silica suspension to $0.05 \mu \mathrm{m}$. The line intercept technique was used to determine the size of matrix $\mathrm{Al}_{2} \mathrm{O}_{3}$ grains. More than 200 grains were counted.

The sintered rectangular bars were machined longitudinally with a 325 grit resin-bonded diamond wheel at a depth of $5 \mu \mathrm{m} /$ pass. The final dimensions of the specimens were $3 \mathrm{~mm} \times 4 \mathrm{~mm} \times 36 \mathrm{~mm}$. The strength of the specimens was determined by four-point bending with the upper and lower spans of 10 and $30 \mathrm{~mm}$, respectively. The rate of loading was $0.5 \mathrm{~mm} / \mathrm{min}$. The fracture toughness was determined by the single-edge-notched-beam (SENB) technique. The notch was generated by cutting with a diamond saw. The width of the notch was approximately $0.3 \mathrm{~mm}$. The elastic modulus of the specimens was determined with an ultrasonic technique at $5 \mathrm{MHz}$.

\section{Results}

The ICP analysis detects only $0.03-0.21 \mathrm{vol} \% \mathrm{Ni}$ in the $\mathrm{Al}_{2} \mathrm{O}_{3}$-Ni powder mixtures (see Table 1). Fig. 1 shows the green density and fired density of the $\mathrm{Al}_{2} \mathrm{O}_{3} / \mathrm{Ni}$ composites as a function of $\mathrm{Ni}$ content. Due to the fact that the $\mathrm{Ni}$ content is very low, the green density and final density of the composites are very similar to each other. The elastic modulus of alumina decreases slightly as a small amount of $\mathrm{Ni}$ is added. The decrease of the elastic modulus can be related to the presence of $\mathrm{Ni}$ inclusions.

Table 1

Nickel content, final density and elastic modulus of the $\mathrm{Al}_{2} \mathrm{O}_{3} / \mathrm{Ni}$ composites

\begin{tabular}{lll}
\hline Ni content (vol.\%) & Relative density (\%) & Elastic modulus (GPa) \\
\hline 0 & 99.9 & 423 \\
0.03 & 99.5 & 417 \\
0.12 & 99.5 & 416 \\
0.13 & 99.3 & 416 \\
0.15 & 99.2 & 411 \\
0.21 & 99.0 & 407 \\
\hline
\end{tabular}

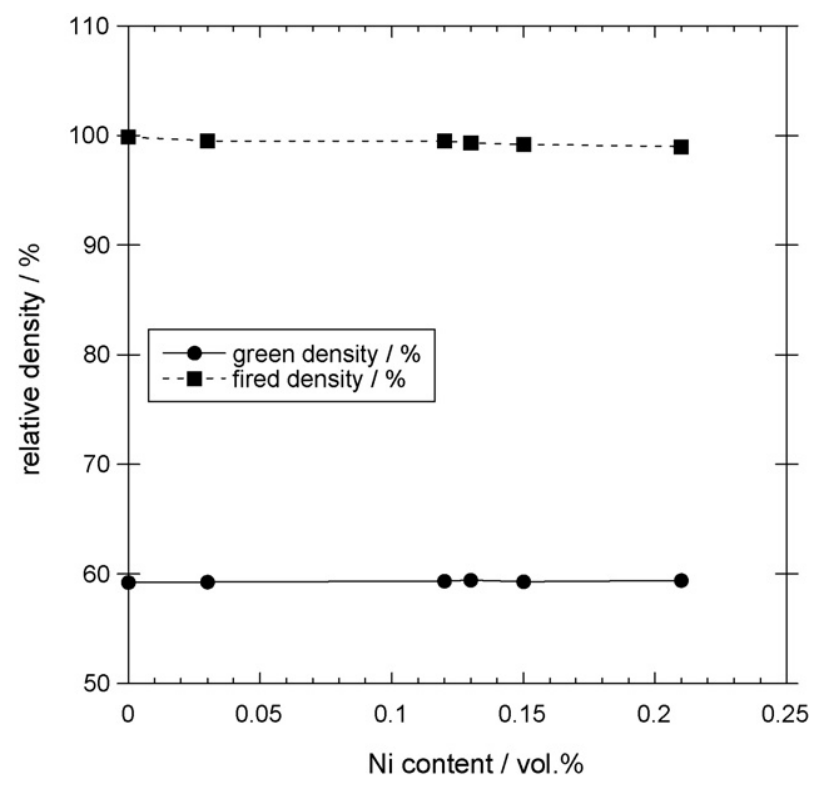

Fig. 1. Green density and sintered density of $\mathrm{Al}_{2} \mathrm{O}_{3} / \mathrm{Ni}$ composites as function of $\mathrm{Ni}$ content.

Fig. 2 shows the SEM micrographs of the fracture surface of composites. Though the amount of $\mathrm{Ni}$ added is very small, the size of $\mathrm{Al}_{2} \mathrm{O}_{3}$ grains decreases significantly with the increase of Ni content. Furthermore, the amount of transgranular fracture increases with the increase of $\mathrm{Ni}$ content. Fine Ni particles with the size around $100 \mathrm{~nm}$ can be found at the grain boundaries of $\mathrm{Al}_{2} \mathrm{O}_{3}$. As the $\mathrm{Ni}$ content is as small as $0.03 \mathrm{vol} . \%$, only several fine $\mathrm{Ni}$ particles can be found for many $\mathrm{Al}_{2} \mathrm{O}_{3}$ grains (see Fig. 2b). The number of Ni particles increases significantly with increasing $\mathrm{Ni}$ content. Almost every $\mathrm{Al}_{2} \mathrm{O}_{3}$ grain in the $\mathrm{Al}_{2} \mathrm{O}_{3} / 0.13 \% \mathrm{Ni}$ composite displays at least one $\mathrm{Ni}$ particle at its own grain boundary. As the Ni content increases from 0.03 to $0.21 \mathrm{vol} . \%$, the size of the Ni particles remains around $100 \mathrm{~nm}$. Fig. 3 shows the size of $\mathrm{Al}_{2} \mathrm{O}_{3}$ grains as a function of Ni content. By adding $0.13 \mathrm{vol} . \% \mathrm{Ni}$, the size of $\mathrm{Al}_{2} \mathrm{O}_{3}$ grains reduces by $50 \%$. Fig. 4 shows the flexural strength of the composites as a function of Ni content. The strength of alumina is enhanced by $35 \%$ and $48 \%$ as only 0.13 and 0.21 vol.\% nano-sized Ni particles are, respectively, added. All the specimens, including the pure alumina specimens, were prepared by pressureless sintering at $1600^{\circ} \mathrm{C}$ for $1 \mathrm{~h}$. The size of the $\mathrm{Al}_{2} \mathrm{O}_{3}$ grains in the pure alumina specimen is large; the strength of the specimen is thus low. The benefit of using fine $\mathrm{Ni}$ inclusions to tailor the microstructure is demonstrated. Fig. 5 shows the fracture toughness of the composites as a function of Ni content. The toughness of alumina is enhanced only by $6 \%$ and $17 \%$ as 0.13 and $0.21 \mathrm{vol} . \% \mathrm{Ni}$ are added, respectively.

\section{Discussion}

The amount of Ni inclusions used in the present study to strengthen $\mathrm{Al}_{2} \mathrm{O}_{3}$ is lower than 0.5 vol.\%. Though the Ni content is low, the coarsening of the $\mathrm{Ni}$ inclusions during sintering 
(a)

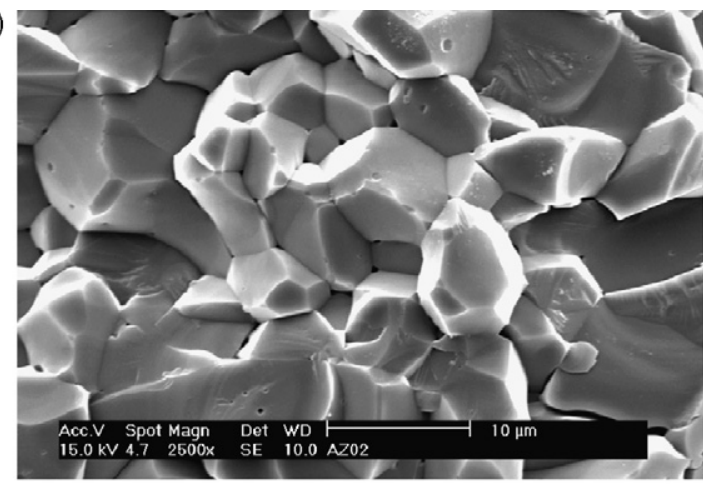

(c)

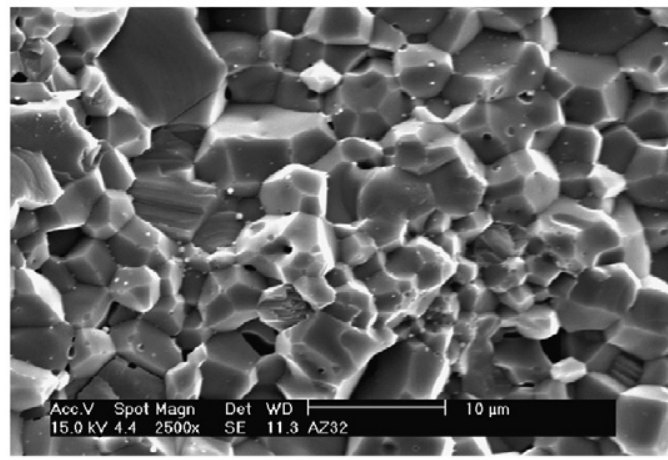

(e)

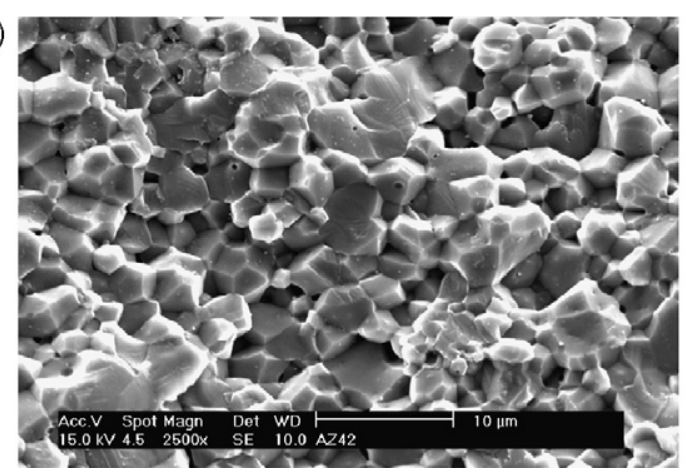

(b)

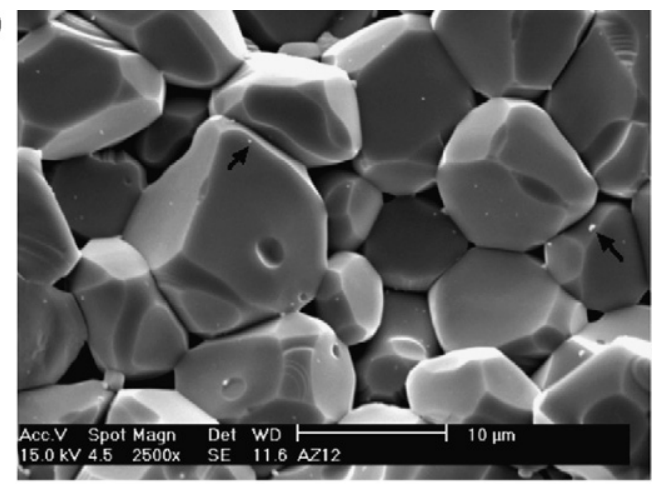

(d)
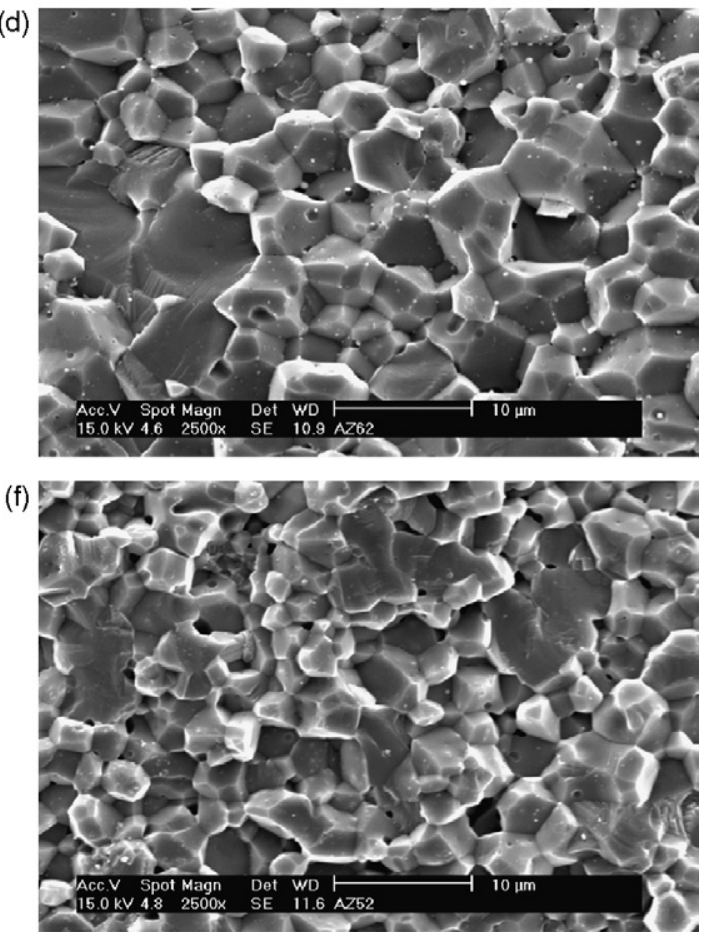

Fig. 2. Typical micrographs of the composites containing: (a) 0 , (b) 0.03 , (c) 0.12 , (d) 0.13 , (e) 0.15 and (f) 0.21 vol.\% Ni. The white fine particles at the grain boundaries of $\mathrm{Al}_{2} \mathrm{O}_{3}$ are $\mathrm{Ni}$ inclusions. Several $\mathrm{Ni}$ inclusions in (b) are arrowed.

is limited. The size of the $\mathrm{Ni}$ inclusions is around $100 \mathrm{~nm}$ in all the $\mathrm{Al}_{2} \mathrm{O}_{3} / \mathrm{Ni}$ composites. Due to the fact that the $\mathrm{Ni}$ inclusions are much smaller than that of $\mathrm{Al}_{2} \mathrm{O}_{3}$ grains, the number of fine $\mathrm{Ni}$ inclusions is much higher than that of $\mathrm{Al}_{2} \mathrm{O}_{3}$ grains. However, the Ni inclusions can be found on the fracture surface of $\mathrm{Al}_{2} \mathrm{O}_{3} / 0.03 \% \mathrm{Ni}$ composite are sparse (see Fig. 2b), implying that many $\mathrm{Ni}$ inclusions are present within the $\mathrm{Al}_{2} \mathrm{O}_{3}$ matrix grains. Furthermore, the size of $\mathrm{Al}_{2} \mathrm{O}_{3}$ grains is little changed due to the presence of $0.03 \mathrm{vol} . \% \mathrm{Ni}$ particles. The strength of the composite is thus very close to that of the pure $\mathrm{Al}_{2} \mathrm{O}_{3}$ specimen (see Fig. 4). It suggests that an amount of 0.03 vol. $\%$ is too low to prohibit the growth of grains.

There are many nano-sized $\mathrm{Ni}$ inclusions found in the $\mathrm{Al}_{2} \mathrm{O}_{3} / 0.13 \%$ Ni composites (see Fig. 2d). Many Ni inclusions are found locating at the boundaries of $\mathrm{Al}_{2} \mathrm{O}_{3}$ grains. Furthermore, at least one $\mathrm{Ni}$ inclusion is found for most $\mathrm{Al}_{2} \mathrm{O}_{3}$ grain boundaries. The size of $\mathrm{Al}_{2} \mathrm{O}_{3}$ grains in the $\mathrm{Al}_{2} \mathrm{O}_{3} / 0.13 \% \mathrm{Ni}$ composites reduces significantly from 10.1 (for pure $\mathrm{Al}_{2} \mathrm{O}_{3}$ ) to $5.3 \mu \mathrm{m}$. It indicates that an amount as low as 0.13 vol. $\%$ of $\mathrm{Ni}$ is sufficient to inhibit the movement of most grain boundaries. As the Ni content becomes higher than 0.13 vol. $\%$, the strength of $\mathrm{Al}_{2} \mathrm{O}_{3} / \mathrm{Ni}$ composites is further enhanced with the increase of $\mathrm{Ni}$ content. Fig. 6 shows the strength of the nanocomposite as a function of the size of $\mathrm{Al}_{2} \mathrm{O}_{3}$ grains. It demonstrates that the $\mathrm{Ni}$ addition is effective to refine the microstructure of $\mathrm{Al}_{2} \mathrm{O}_{3}$. The slope of the straight line shown in the figure is $-1 / 2$, indicating that the strength of the nanocomposites follows the Griffith-Orowan relationship. ${ }^{6}$ The strengthening effect can thus be related to the microstructure refinement. Though the size of $\mathrm{Al}_{2} \mathrm{O}_{3}$ grains decreases with increasing Ni content, the amount of transgranular fracture increases with $\mathrm{Ni}$ content. It indicates that the grain boundary strengthening mechanism ${ }^{7,8}$ also contributes partly to the strength enhancement for the nanocomposites.

It is of interest to estimate the minimum amount of nano-sized $\mathrm{Ni}$ particles needed to prohibit the grain growth of $\mathrm{Al}_{2} \mathrm{O}_{3}$ grains. Assuming that there are $n$ inclusions at one grain boundary as the case shown in Fig. 7, the volume fraction of the inclusions 


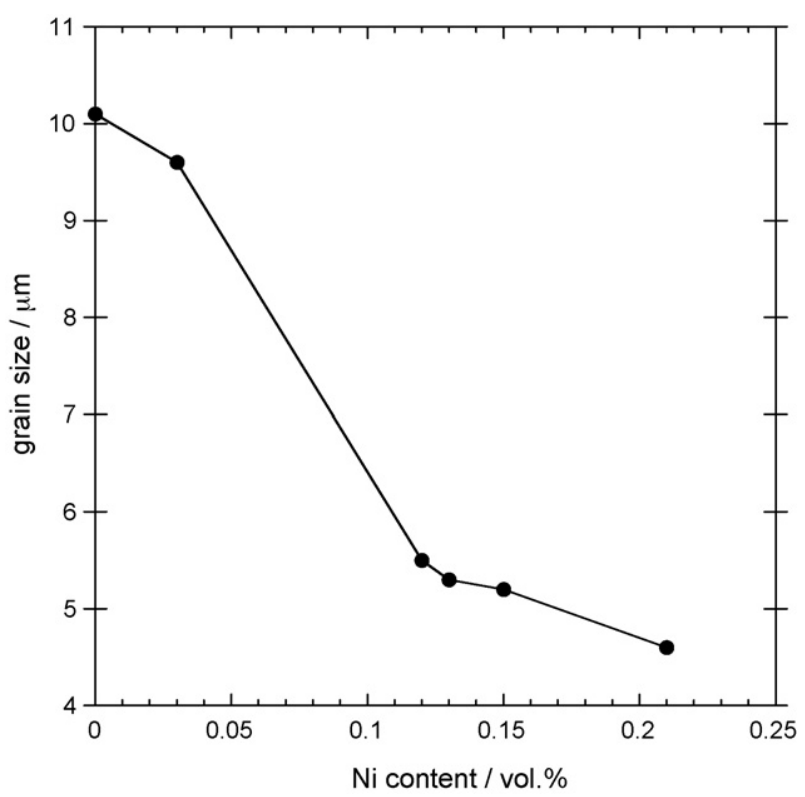

Fig. 3. Size of $\mathrm{Al}_{2} \mathrm{O}_{3}$ grains in the composites as function of $\mathrm{Ni}$ content.

can be estimated as

$F=n\left(\frac{d}{G}\right)^{3}\left(\frac{14}{2}\right)$

where $F$ is the volume fraction, $d$ the inclusion size and $G$ is the grain size. There are 14 faces for each polyhedron; therefore, a constant $14 / 2$ is used in the above equation. The minimum volume fraction corresponds to the case that the number of inclusion at each grain boundary is one $(n=1)$. For the case that $G=1 \mu \mathrm{m}$ and $d=100 \mathrm{~nm}$, the minimum volume fraction is only $0.7 \mathrm{vol} . \%$. Furthermore, the minimum volume fraction drops quickly with the increase of grain size.

The equation above demonstrates that the minimum amount needed to prohibit the growth of matrix grains depends strongly

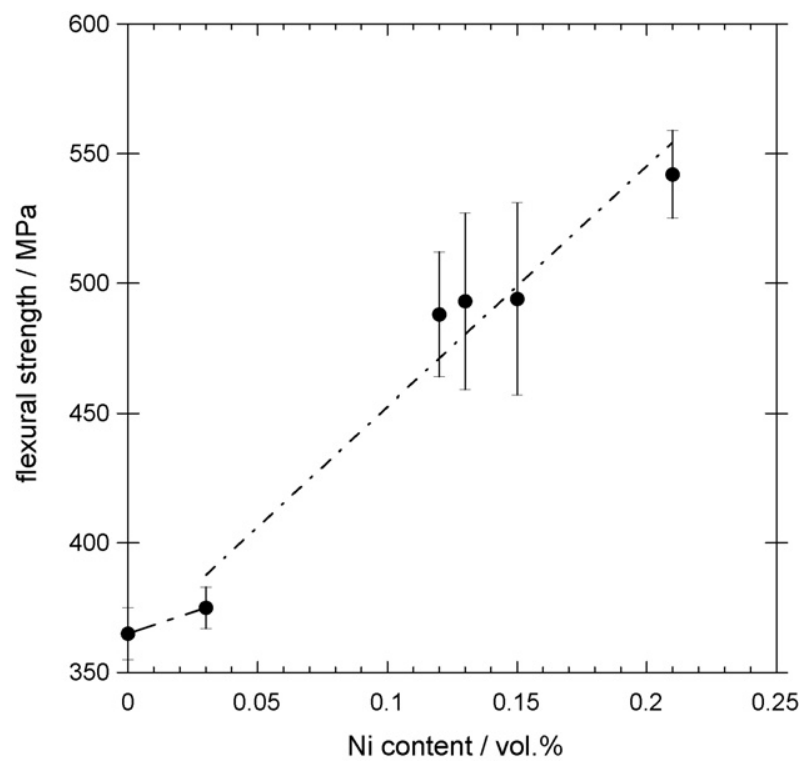

Fig. 4. Strength of the $\mathrm{Al}_{2} \mathrm{O}_{3} / \mathrm{Ni}$ composites as function of $\mathrm{Ni}$ content.

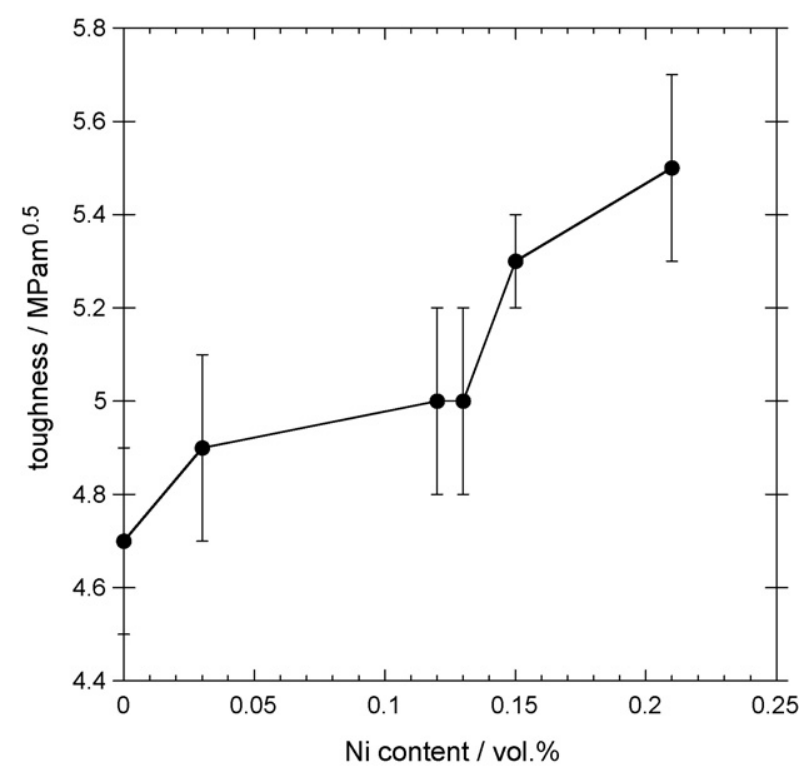

Fig. 5. Toughness of the $\mathrm{Al}_{2} \mathrm{O}_{3} / \mathrm{Ni}$ composites as function of $\mathrm{Ni}$ content.

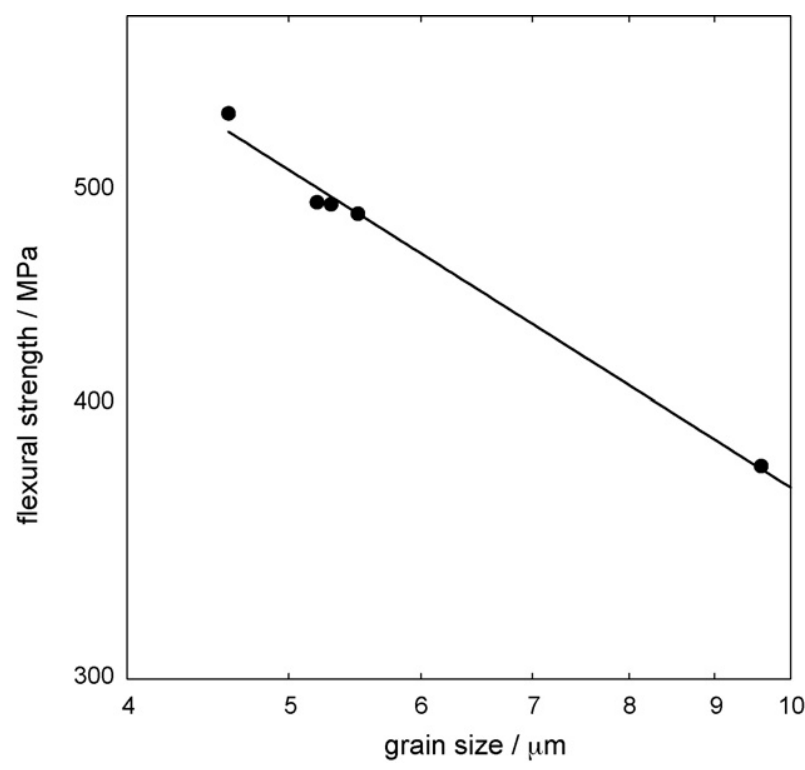

Fig. 6. Strength of $\mathrm{Al}_{2} \mathrm{O}_{3} / \mathrm{Ni}$ composites as function of $\mathrm{Al}_{2} \mathrm{O}_{3}$ grain size.

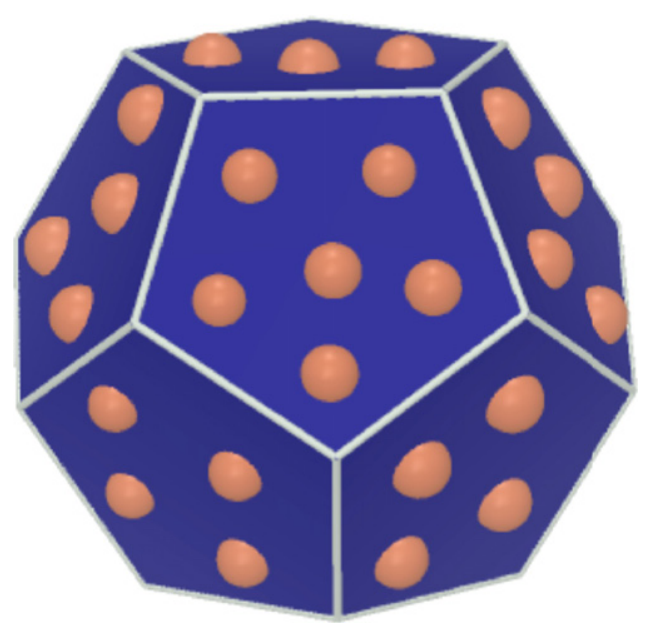

Fig. 7. Schematic of a grain with inclusions at its boundaries. 
on the ratio of inclusion size over grain size. For the $\mathrm{Al}_{2} \mathrm{O}_{3} / \mathrm{Ni}$ nanocomposites prepared in the present study, the size of $\mathrm{Ni}$ inclusions is around $100 \mathrm{~nm}$, the ratio of inclusion size over grain size varies from 0.02 to 0.1 . The equation suggests an amount below 0.7 vol. $\%$ is enough to deliver a refined microstructure. The experimental result matches well with the analysis. As the number of inclusions at each grain boundary is higher than unity, $n>1$, the capability of the inclusion to prohibit the growth of matrix is further enhanced. Therefore, $n=1$ can be treated as the minimum value needed to improve the strength of composite.

However, there are two limits on the minimum amount of inclusion. Firstly, the inclusion content has to be higher than the solubility of inclusion in matrix. Secondly, the inclusion should not breakaway from the grain boundary. However, both the boundary of matrix grain and inclusion can move during sintering. As the velocity of grain boundary, $v_{\mathrm{b}}$, is much higher than that of inclusion, $v_{\mathrm{i}}$, as shown in the following equation.

$v_{\mathrm{b}}>v_{\mathrm{i}}^{\max }$

the breakaway can take place. By adopting the relationships for the separation between pore and grain boundary, ${ }^{9}$ the criteria for the breakaway can be estimated. For the grain boundary, its mobility is controlled by the diffusion across the grain boundary, $D^{*}$, the Boltzmann's constant, $k$, and the absolute temperature, $T$. The force on the grain boundary is controlled by the grain boundary energy, $\gamma_{\mathrm{gb}}$, and grain size, $G$. The velocity of boundary, $v_{\mathrm{b}}$, can then be expressed as, ${ }^{9}$

$v_{\mathrm{b}}=M_{\mathrm{b}} F_{\mathrm{b}}=\frac{D^{*}}{k T} \frac{\gamma_{\mathrm{gb}}}{G}$

The movement of the inclusion is a diffusional process, an effective diffusion coefficient, $D_{\text {eff }}$, to illustrate the mobility of the inclusion is used as, ${ }^{10}$

$M_{\mathrm{i}}=\frac{D_{\mathrm{eff}} \Omega}{k T d^{m}}$

where $\Omega$ is the volume of controlling ions, $m$ a constant depending on the mechanism. The force on the inclusion is also provided by the grain boundary energy. The force on an inclusion is expressed as. ${ }^{9}$

$F_{\mathrm{i}}=2 \pi d \gamma_{\mathrm{gb}}$

The velocity of particle, $v_{\mathrm{i}}$, is

$v_{\mathrm{i}}=M_{\mathrm{i}} F_{\mathrm{i}}=\frac{D_{\mathrm{eff}} \Omega}{k T d^{m}} 2 \pi d \gamma_{\mathrm{gb}}$

By comparing Eqs. (3) and (6), the following equation is obtained,

$\frac{D^{*}}{2 \pi D_{\text {eff }} \Omega}>\frac{G}{d^{m-1}}$

The analysis above demonstrates that there is a critical value for the ratio of grain size over inclusion size. Since the coarsening of inclusions is limited as the second phase amount is low, the breakaway of the grain boundary and inclusion is virtually controlled by the growth of matrix grains. From the microstructure observation, the critical size for the $\mathrm{Al}_{2} \mathrm{O}_{3}$ grain boundary to breakaway from the $\mathrm{Ni}$ inclusion is around $10 \mu \mathrm{m}$. The analysis above demonstrates that there is a critical amount for the second phase to prohibit the coarsening of matrix grains. The critical amount of the second phase is a function of the ratio of grain size over particle size. For the present system under the processing conditions used, the critical amount of inclusions is only 0.1 vol. $\%$.

The toughness of $\mathrm{Al}_{2} \mathrm{O}_{3} / \mathrm{Ni}$ also increases with the increase of $\mathrm{Ni}$ content (see Fig. 5); though the increase is relatively marginal comparing to strength increase. The $\mathrm{Al}_{2} \mathrm{O}_{3}-\mathrm{Ni}$ interface is relatively weak, ${ }^{4}$ the presence of such weak interface encourages the deflection of crack path.

\section{Conclusions}

In the present study, the $\mathrm{Al}_{2} \mathrm{O}_{3} / \mathrm{Ni}$ nanocomposites with $\mathrm{Ni}$ content smaller than $0.21 \mathrm{vol} \%$ are prepared by pressureless sintering. The strength of the $\mathrm{Al}_{2} \mathrm{O}_{3} / 0.21 \% \mathrm{Ni}$ composite is $50 \%$ higher than that of monolithic $\mathrm{Al}_{2} \mathrm{O}_{3}$. Both the microstructure refinement and grain boundary strengthening contribute to the strength increase. The implications can be drawn from the present study are:

(1) The amount of second phase needed to increase the strength of composite depends strongly on the sizes of matrix grains and of second phase.

(2) As far as the preparation of nanocomposite is concerned, the amount of nano-sized particles can be very low. As the amount of the nano-sized particles is low, the densification of the nanocomposite is no longer difficult.

\section{References}

1. Rice, R. W., Microstructure dependence of mechanical behavior of ceramics. Treatise Mater. Sci. Tech., 1977, 11, 197-381.

2. Wei, G. C. and Becher, P. F., Development of SiC-whisker-reinforced ceramics. Am. Ceram. Soc. Bull., 1985, 64(2), 298-304.

3. Sekino, T., Nakajima, T., Ueda, S. and Niihara, K., Reduction and sintering of a nickel-dispersed-alumina composite and its properties. J. Am. Ceram. Soc., 1997, 80(5), 1139-1148.

4. Chen, R. Z. and Tuan, W. H., Pressureless sintering of $\mathrm{Al}_{2} \mathrm{O}_{3} / \mathrm{Ni}$ nanocomposites. J. Eur. Ceram. Soc., 1999, 19(4), 463-468.

5. Tuan, W. H. and Brook, R. J., The toughening of alumina with nickel inclusions. J. Eur. Ceram. Soc., 1990, 6(1), 31-37.

6. Chantikul, P., Bennison, S. J. and Lawn, B. R., Role of grain size in the strength and R-curve properties of alumina. J. Am. Ceram. Soc., 1990, 73(8), 2419-2427.

7. Jiao, S., Jenkins, M. L. and Davidge, R. W., Interfacial fracture energy-mecnahical behavior relationship in $\mathrm{Al}_{2} \mathrm{O}_{3} / \mathrm{SiC}$ and $\mathrm{Al}_{2} \mathrm{O}_{3} / \mathrm{TiN}$ nanocomposites. Acta Mater., 1997, 45(1), 149-156.

8. Sternitzke, M., Review: structural ceramic nanocomposites. J. Eur. Ceram. Soc., 1997, 17(5), 1061-1082.

9. Brook, R. J., Controlled grain growth. Treatise Mater. Sci. Tech., 1976, 9, 331-364.

10. Tuan, W. H, Chen, J. R. and Ho, C. J. Critical zirconia amount to enhance the strength of alumina. Ceram. Int., submitted for publication. 